\title{
The 2016 Kumamoto-Oita earthquake sequence: aftershock seismicity gap and dynamic triggering in volcanic areas
}

\author{
Takahiko Uchide ${ }^{1 *}$ (D), Haruo Horikawa', Misato Nakai', Reiken Matsushita', Norio Shigematsu', Ryosuke Ando ${ }^{2}$ \\ and Kazutoshi Imanishi ${ }^{1}$
}

\begin{abstract}
The 2016 Kumamoto-Oita earthquake sequence involving three large events $\left(M_{w} \geq 6\right)$ in the central Kyushu Island, southwest Japan, activated seismicities in two volcanic areas with unusual and puzzling spatial gaps after the largest earthquake $\left(M_{w}\right.$ 7.0) of April 16, 2016. We attempt to reveal the seismic process during the sequence by following seismological data analyses. Our hypocenter relocation result implies that the large events ruptured different faults of a complex fault system. A slip inversion analysis of the largest event indicates a large slip in the seismicity gap (Aso gap) in the caldera of Mt. Aso, which probably released accumulated stress and resulted in little aftershock production. We identified that the largest event dynamically triggered a mid-M6 event at Yufuin (80 km northeast of the epicenter), which is consistent with existence of the 20-km long zone where seismicity was activated and surface offset was observed. These findings will help us study the contribution of the identified complexity in fault geometries and the geotherm in the volcanic areas to the revealed seismic process and consequently improve our understanding of the seismo-volcano tectonics.
\end{abstract}

\section{Introduction}

Tectonic faults often lie near volcanoes (Azzaro 1999; Nishigami 1997), and therefore, large inland earthquakes sometimes strike volcanic regions (Ando and Okuyama 2010; Moran et al. 2002). The elucidation of the influence of volcanic areas, in addition to the fault geometries and other properties, on earthquake generation is essential for better understanding of the seismo-volcano tectonics as well as for improvement in the accuracy of natural hazard evaluation.

Recently, the 2016 Kumamoto-Oita, southwest Japan, earthquake sequence occurred through volcanic areas in the central Kyushu Island, across which the BeppuShimabara graben lies oriented from the northeast to the southwest (Matsumoto 1979). Along the graben large fault systems are present under the north-south

\footnotetext{
*Correspondence: t.uchide@aist.go.jp

${ }^{1}$ Geological Survey of Japan, National Institute of Advanced Industrial Science and Technology (AIST), 1-1-1 Higashi, AIST Central 7, Tsukuba, Ibaraki 305-8567, Japan

Full list of author information is available at the end of the article
}

extensional stress regime, which produces both strikeslip and normal faulting earthquakes (Matsumoto et al. 2015). The fault systems are the Beppu-Haneyama fault system in the northeast, the Futagawa fault system in the center, and the Hinagu fault system in the southwest (Fig. 1). The latter two fault systems are largely northwestward-dipping dextral strike-slip faults (The Headquarters for Earthquake Research Promotion 2002, 2013). Additionally, several volcanoes, including Mt. Aso, and geothermal areas lie along the Beppu-Shimabara graben.

This earthquake sequence broke out in the Kumamoto Prefecture at 21:26 on April 14, 2016 [hereafter all times are written using the Japan Standard Time (UTC +9 )] by an $M_{\mathrm{w}} 6.2$ event (hereafter "event $\alpha$ "), which gave rise to devastating ground motion, followed by an $M_{\mathrm{w}} 6.0$ event ("event $\beta$ ") at 0:03 on April 15, 2016, located at a distance of only $10 \mathrm{~km}$ south from the event $\alpha$ (Fig. 1). An even larger and, so far, the largest event $\left(M_{\mathrm{w}} 7.0\right.$; "event $\gamma$ ") struck at 1:25 on the 16th near the event $\alpha$ and caused further damage through the strong ground-shaking in the surrounding area. The hypocenters of all three events 


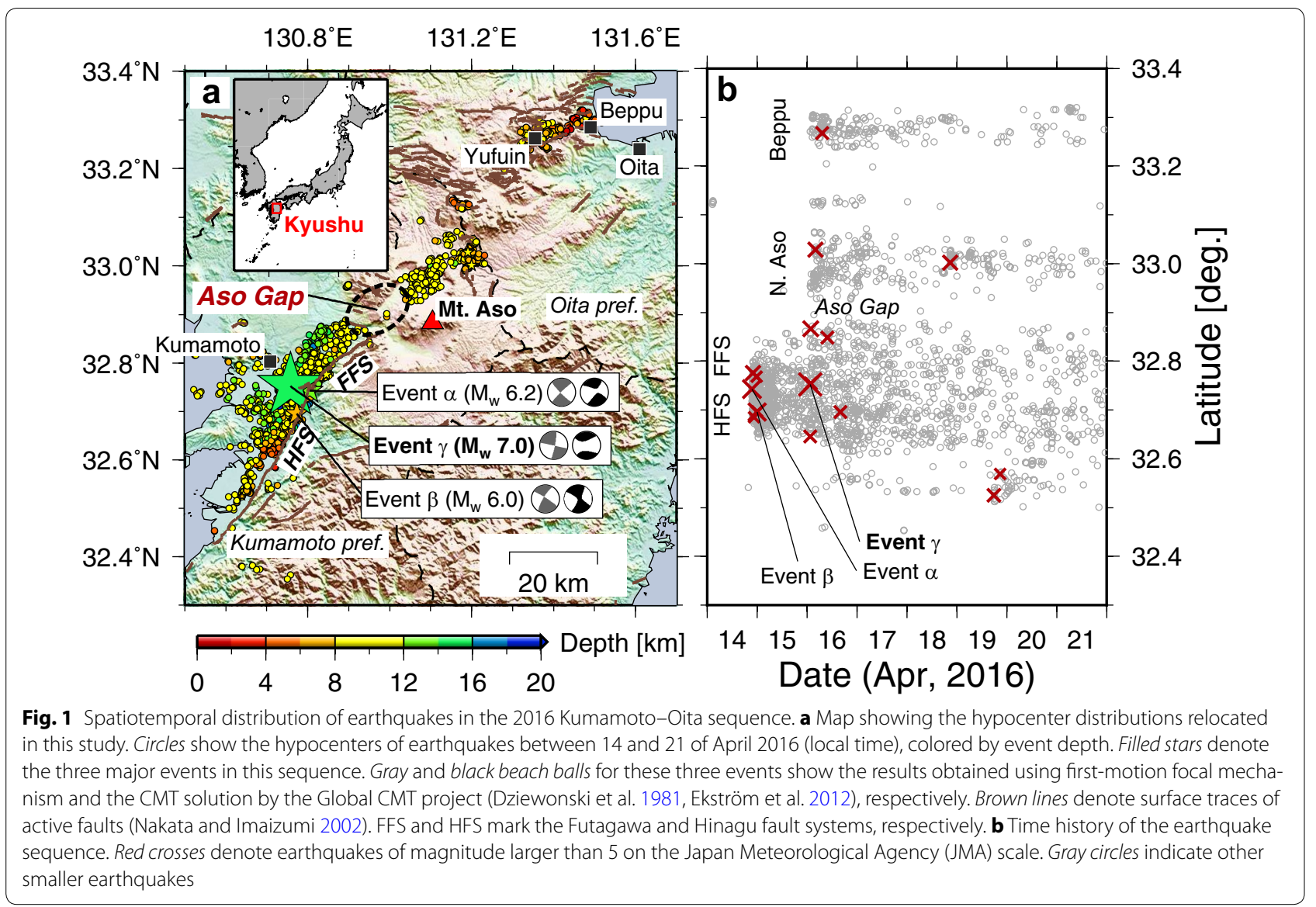

were located along the Futagawa and Hinagu fault systems. Following the event $\gamma$, the seismicities in two volcanic areas, the northern Aso and Yufuin-Beppu areas, became active. In addition, seismicity gaps are also observed between the Futagawa fault system and the northern Aso area (we refer to this gap as the Aso gap), and between the northern Aso and the Yufuin-Beppu areas.

This earthquake sequence raises several questions: Why were these faults ruptured not by a single large earthquake but by three successive ones? What caused the seismic gaps? Toward addressing these questions, phenomenological understanding of this earthquake sequence is essential. This paper presents following seismological observations: the underground fault geometry of the Hinagu and Futagawa fault systems inferred from distribution of aftershocks refined by an earthquake relocation analysis; the relationship between the Aso gap and the rupture process of the largest shock, event $\gamma$, inferred from a finite fault slip inversion using strong-motion data; and a detection and quantification of a dynamic triggering event in the Yufuin-Beppu area, Oita prefecture. Based on these observations, we will show a perspective to solve the abovementioned questions.

\section{Seismic velocity structure used in seismological analyses}

At the first step of the following seismological analyses, we constructed a one-dimensional underground structure of seismic velocity and quality factor (Fig. 2; Table 1), following the three-dimensional tomography of entire Japan (Matsubara et al. 2008) for the seismic velocity at depths $>5 \mathrm{~km}$ and the subsurface structure provided in J-SHIS of the National Research Institute for Earth Science and Disaster Resilience (NIED) (Fujiwara et al. 2009, 2012) for seismic velocity at depths $<5 \mathrm{~km}$ and the quality factor. The seismic velocities as a function of depth in the tomography of Matsubara et al. (2008) do not vary very much in the Kyushu region (Fig. 2); therefore, we expect that the one-dimensional model will work well.

\section{Geometries of underground faults in Futagawa and Hinagu fault systems}

We investigated the geometries of faults over which the three large events occurred, based on relocated hypocenters in the entire region shown in Fig. 1. The relocation was conducted with the hypoDD program (Waldhauser and Ellsworth 2000), using 282,999 and 253,335 arrival time differences for the P- and S-waves, 

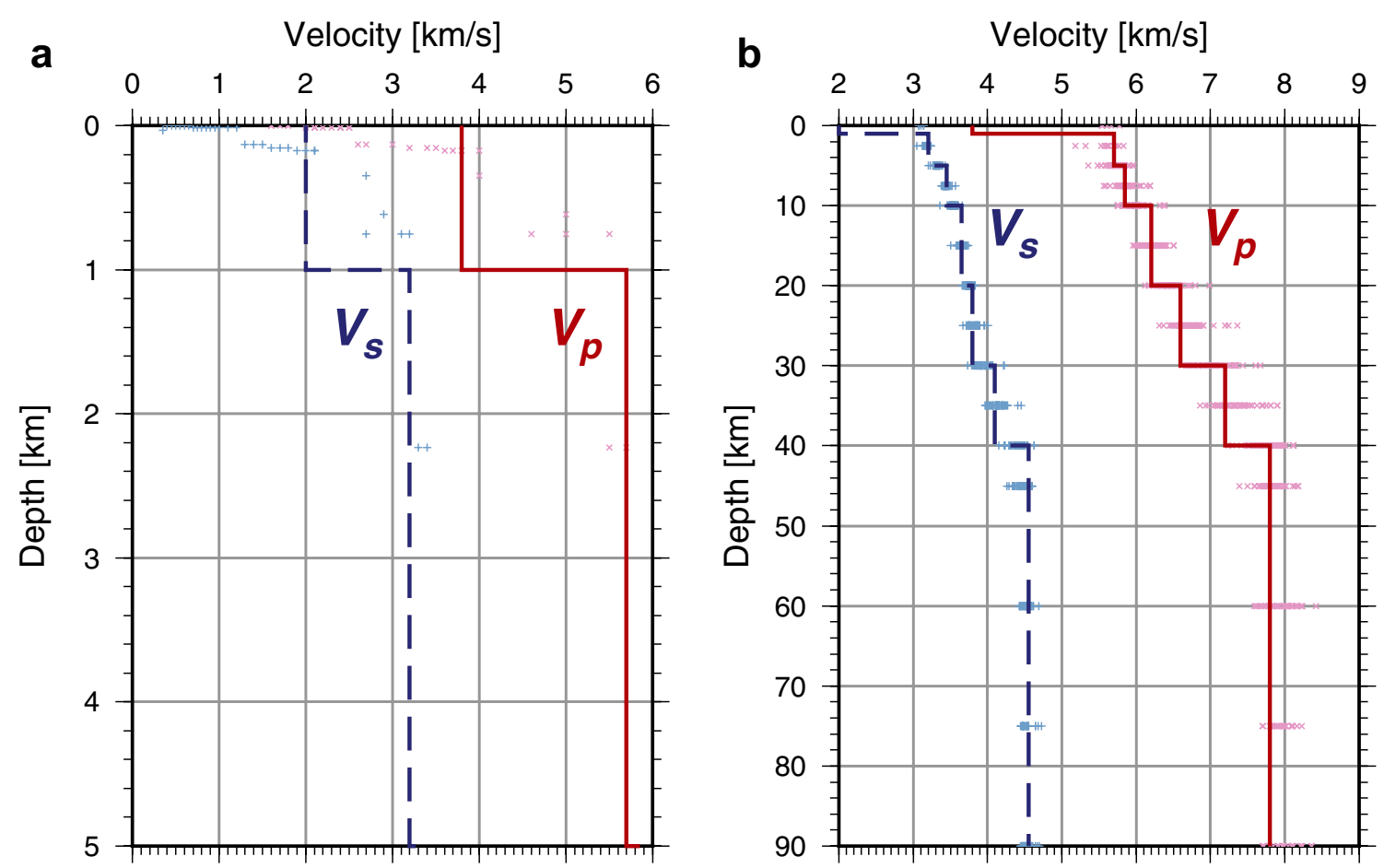

Fig. 2 Velocity structure constructed and used in this study. a Structure at shallow depths down to $5 \mathrm{~km}$. Red solid lines and blue dashed lines indicate the P- and S-wave velocities, respectively. Pink and light blue dots denote the median of P-and S-wave velocities, respectively, in the Kyushu region from the subsurface structure provided in J-SHIS of NIED (Fujiwara et al. 2009, 2012). b Structure at depth down to $90 \mathrm{~km}$. Here, pink and light blue dots indicate P- and S-wave velocities, respectively, in the Kyushu region from the three-dimensional tomography of entire Japan (Matsubara et al. 2008)

Table 1 One-dimensional seismic velocity and attenuation structure

\begin{tabular}{lllll}
\hline Depth $(\mathbf{k m})$ & $\boldsymbol{V}_{\mathbf{p}}(\mathbf{k m} / \mathbf{s})$ & $\boldsymbol{V}_{\mathbf{s}}(\mathbf{k m} / \mathbf{s})$ & $\boldsymbol{Q}_{\mathbf{p}}$ & $\boldsymbol{Q}_{\mathbf{s}}$ \\
\hline $0-1$ & 3.80 & 2.00 & 200 & 200 \\
$1-5$ & 5.70 & 3.20 & 300 & 300 \\
$5-10$ & 5.85 & 3.45 & 300 & 300 \\
$10-20$ & 6.20 & 3.65 & 300 & 300 \\
20-30 & 6.60 & 3.80 & 300 & 300 \\
$30-40$ & 7.20 & 4.10 & 400 & 400 \\
40- & 7.80 & 4.55 & 500 & 500 \\
\hline
\end{tabular}

$V_{p}$ and $V_{s}$ denote velocities of $P$ - and $S$-waves, respectively. $Q_{p}$ and $Q_{s}$ are quality factors for P-and S-waves, respectively

respectively. These arrival times are picked for 2770 events that occurred between 14 and 21 of April 2016, and listed on the Japan Meteorological Agency (JMA) Unified Earthquake Catalog.

For calculating double-difference of arrival times, we allow that each event have up to 15 neighbors within $10 \mathrm{~km}$ according to the JMA catalog. Each pair must have 8 or more of travel time difference data from either P- or $\mathrm{S}$-arrivals from stations within $100 \mathrm{~km}$ from event locations. We gave half of weights for S-arrival times than
P-arrival times. Finally, we successfully relocated the 2370 events, reducing the weighted root-mean-square of the residual times from 0.1436 to $0.0510 \mathrm{~s}$ (Additional file 1: Figure S1).

Figure 3 shows the distribution of the relocated hypocenters, suggesting the geometries of the ruptured faults with significantly high clarity. The relocated hypocenters indicate northwest-dipping faults and two nearly vertical faults in the Futagawa and Hinagu fault systems. To clearly show the three-dimensional distribution of the hypocenters, this fault configuration is highlighted in Additional file 2: Movie S1. The dipping faults correspond well to the centroid moment tensor (CMT) solutions of the three large events by the Global CMT Project (Dziewonski et al. 1981; Ekström et al. 2012) (Fig. 1a), and the Futagawa (A-A' to $\mathrm{C}-\mathrm{C}^{\prime}$ cross sections in Fig. $3 \mathrm{~b}$ ) and Hinagu faults (G-G' to $I-\mathrm{I}^{\prime}$ cross sections), although the correspondence is not clear in the middle part $\left(\mathrm{D}-\mathrm{D}^{\prime}\right.$ to $\left.\mathrm{F}-\mathrm{F}^{\prime}\right)$.

The result implies that the three major events ruptured the fault planes of different geometries. The spatial distributions of small earthquakes before and after the event $\gamma$ are clearly different. The event $\alpha$ was initiated on the vertical fault (E-E' cross section in Fig. 3b), as also implied 


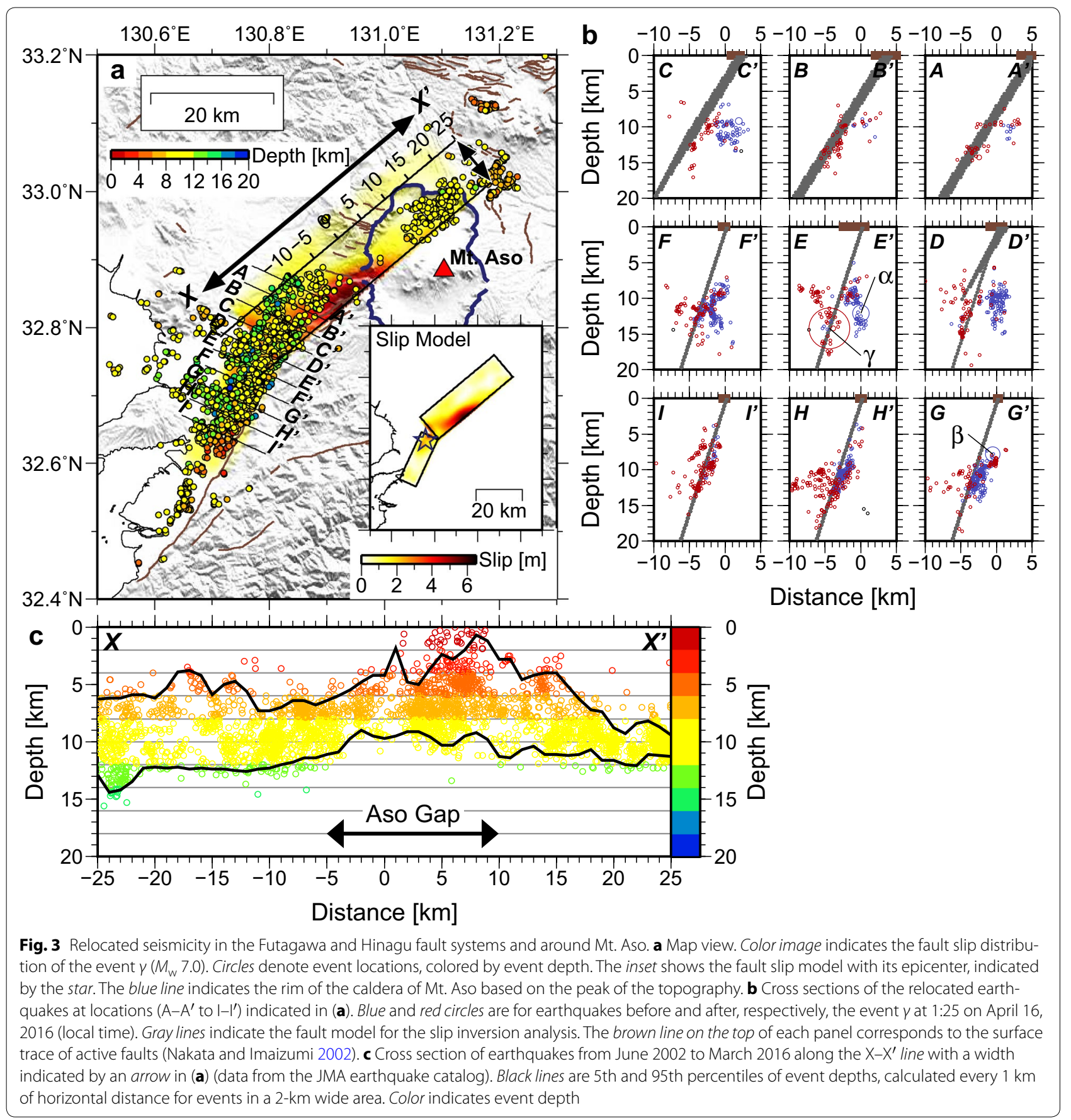

by the first-motion focal mechanism (Fig. 1a) estimated from seismograms of KiK-net (Okada et al. 2004), the HASH code (Hardebeck and Shearer 2002), and the velocity structure (Fig. 2; Table 1). The event $\beta$ was initiated on the steeply dipping fault rather than vertical one, and the nucleation of the event $\gamma$ occurred on another vertical fault. Several earthquakes preceded the event $\gamma$ around its hypocenter (E-E' cross section in Fig. $3 b)$. This activity started right after the occurrence of the event $\alpha$.
We do not see increase in seismicity rate of this activity. On the basis of a catalog constructed with a matched filter technique, Kato et al. (2016) showed migrations of seismicity following the event $\alpha$, which also propagated to the nucleation point of the events $\beta$ and $\gamma$.

\section{Slip distribution of the largest event and Aso Gap}

In order to evaluate the influence of the event $\gamma$ on the Aso gap, we performed a slip inversion analysis with the 
multi-time window (Hartzell and Heaton 1983) using the seismograms from $17 \mathrm{KiK}$-net borehole stations (Fig. 4a) and a previously developed computer code (Uchide and Ide 2007). Note that we did not use seismic stations in Oita prefecture to avoid possible contamination by a dynamically triggered event discussed in "Dynamic triggering in Yufuin-Beppu area" section.

We defined a fault model composed of two planes (Fig. 4a; Table 2) corresponding to the Hinagu and Futagawa faults, to fit the relocated hypocentral distribution (Fig. 3b). The separation of the two planes in a deeper part comes from the limitation of the approximation with planes. We determined the fault length based on the discontinuities of fringes in the In-SAR image (Geospatial Information Authority of Japan 2016). As a whole, the fault is $65 \mathrm{~km}$ long and $25 \mathrm{~km}$ wide.

We express the slip direction between those corresponding to the pure normal faulting and the pure rightlateral strike-slip faulting by their summation. On the fault planes, we placed one-dimensional spline functions ("triangular functions") every $2.5 \mathrm{~km}$ in space and every $2 \mathrm{~s} \mathrm{in}$ time to represent the spatiotemporal distribution of the fault slip velocity. The time windows on the faults are open for $12 \mathrm{~s}$ from the time when a hypothetical rupture front with the velocity of $3.0 \mathrm{~km} / \mathrm{s}$ arrives from the hypocenter.

We inverted the displacement waveforms obtained by integrating the original acceleration data twice after the removal of the offset and bandpass-filtering between 0.025 and $0.25 \mathrm{~Hz}$. Moreover, we resampled the data every $0.4 \mathrm{~s}$.

We calculated the Green's functions using the onedimensional seismic velocity model (Fig. 2; Table 1) by the reflection-transmission matrix method (Kennett and Kerry 1979) and wavenumber integral method (Bouchon 1981) while accounting for anelastic attenuation (Takeo 1985).

We aligned the data and the Green's functions by $\mathrm{S}$-arrivals to suppress bias of unmodeled lateral variation of velocity structure. Actually, we performed the alignment from P-arrival of the event $\gamma$, and S-P time of a collocated event $\left(M_{\mathrm{j}} 4.3\right)$ that occurred at 4:51 on April 16, 2016, was measured using Hi-net or KiK-net data at the same boreholes. This is because we found it difficult to pick the $\mathrm{S}$-arrivals for the event $\gamma$ due to the overlapping $P$ waves,

We inverted the data using the nonnegative least square algorithm (Lawson and Hanson 1995) with a spatial smoothing constraint. The intensity was objectively set in such a way as to minimize the Akaike's Bayesian Information Criterion (Uchide and Ide 2007; Yabuki and Matsu'ura 1992).

The waveform fits by the estimated model (Figs. 3a, 4c, d) are shown in Fig. 4b. The variance reduction (ratio of the variance of the residual to that of the data) was $71 \%$, which is quite reasonable. The estimated model yields a seismic moment of $5.1 \times 10^{19} \mathrm{Nm}\left(M_{\mathrm{w}} 7.1\right)$ and implies that the fault rupture extends below the northern part of the Aso caldera, rupturing the shallow portion of the Aso gap by the oblique slip with a peak slip of around $6 \mathrm{~m}$. Few fore- and aftershocks occurred in the large slip areas. This result has an overall similarity to a model proposed by Yagi et al. (2016) inferred from teleseismic data. The existence of the large slip area penetrating the Aso caldera is also supported by the field observation of the surface rupture (Shirahama et al. 2016) and the InSAR analysis (Geospatial Information Authority of Japan 2016).

\section{Dynamic triggering in Yufuin-Beppu area}

In the Yufuin-Beppu area, we investigated the beginning of seismicity by a visual inspection of seismic waveforms from the event $\gamma$ observed in this area and identified an earthquake in the wave trains from the event $\gamma$ (Fig. 5b) and located its hypocenter using manually picked P- and S-wave arrival times and the hypomh code (Hirata and Matsu'ura 1987). When picking the arrival times, we applied a high-pass filter at $16 \mathrm{~Hz}$ to the original seismograms in order to emphasize the local event, because the amplitudes in seismic waves from the event $\gamma$ at higher frequencies are reduced due to the anelastic attenuation effect. The estimated hypocenter is located at $33.266 \mathrm{~N}$, $131.340 \mathrm{E}$ at a depth of around $5 \mathrm{~km}$ with 0.5 and $1.1 \mathrm{~km}$ of the horizontal and vertical location errors, respectively, beneath the Yufuin area at the western edge of the activated seismic area (Fig. 5a). This event occurred $32.6 \mathrm{~s}$ after the onset of the event $\gamma$ and surely after the termination of the event $\gamma$, the source duration of which is shorter than $30 \mathrm{~s} \mathrm{(Fig.} \mathrm{4c).} \mathrm{Around} \mathrm{the} \mathrm{origin} \mathrm{time} \mathrm{of}$ the identified event, large low-frequency waves ( $\mathrm{S}$ wave or Rayleigh wave according to the travel time) were observed at OIT009, the closest station to the hypocenter of the identified event (Fig. 5d), which implies the dynamic triggering, as often done by large earthquakes (Anderson et al. 1994), especially in volcanic areas (Brodsky et al. 2000; Gomberg et al. 2001; Hill and Prejean 2007; Kilb et al. 2000; Yukutake et al. 2012). Note that the peak ground acceleration at OIT009 was brought by the triggered event, not the event $\gamma$.

The magnitude estimation of the triggered event is challenging due to the overlapping seismic waves from the event $\gamma$, especially at low frequencies. JMA preliminarily reported the JMA magnitude of 5.7 using velocity seismograms from two stations. Here, we attempt to estimate the moment magnitude of the triggered event based on the amplitude ratios between the triggered event and the nearby $M_{\mathrm{w}} 5.1$ event that occurred at 7:11 on April 16, 


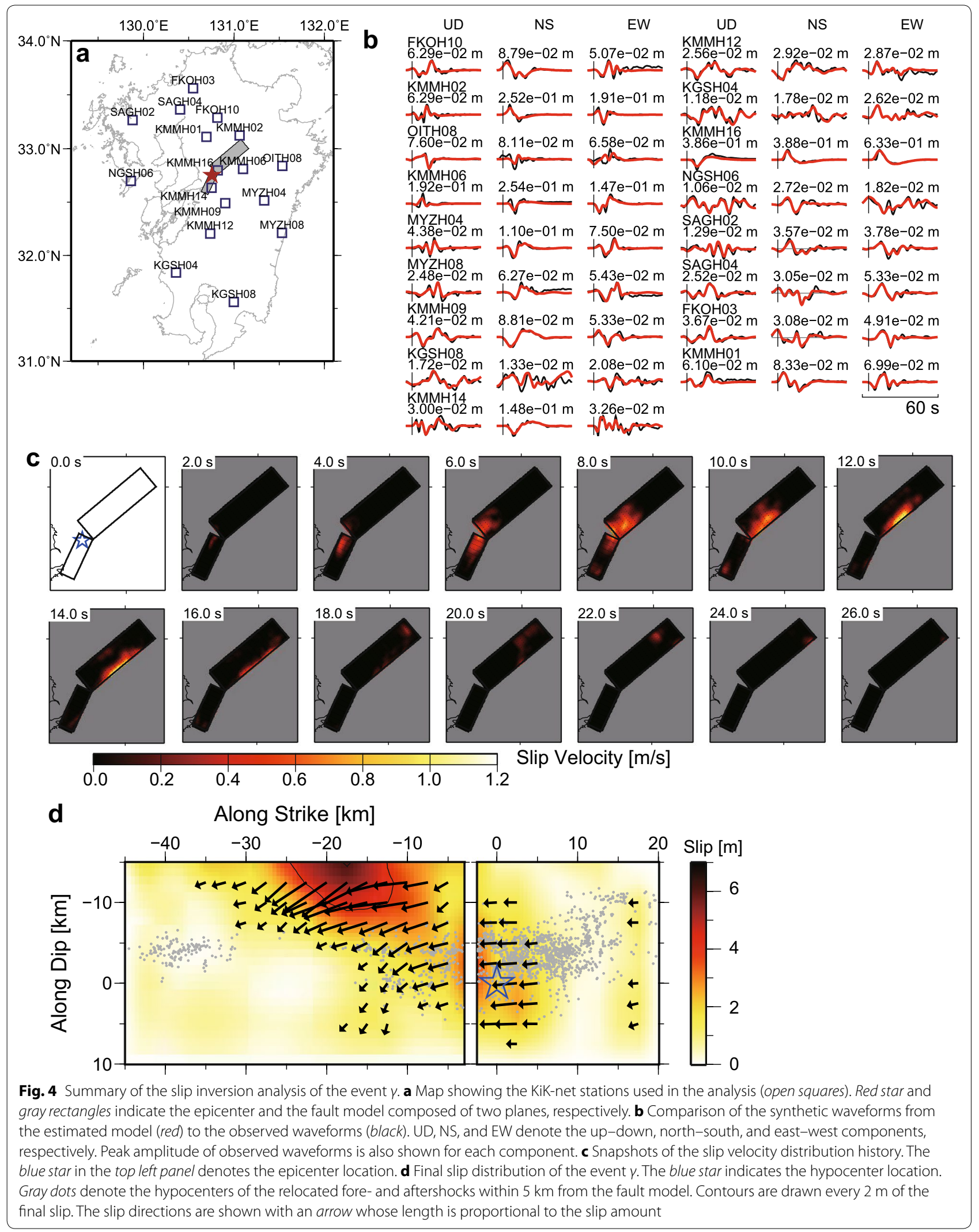


Table 2 Geometry of the fault model for the slip inversion analysis

\begin{tabular}{lllll}
\hline & Strike (deg.) & Dip (deg.) & Length $(\mathbf{k m})$ & Width $(\mathbf{k m})$ \\
\hline NE & 230 & 60 & 42.5 & 25 \\
SW & 205 & 72 & 22.5 & 25 \\
\hline
\end{tabular}

$N E$ and SW denote the northeastern and southwestern segments, respectively

2016. While the amplitudes are affected during wave propagation, the co-located events were influenced equally; hence, the wave propagation effect does not significantly bias the amplitude ratio. Here, we focused on high-frequency components, in which the seismic wave from the event $\gamma$ is weak relative to the triggered event due to the anelastic attenuation. According to the $\omega^{2}$ model (Aki 1967), the source spectrum is given by

$$
\widetilde{M}_{\mathrm{o}}(f)=\frac{M_{\mathrm{o}}}{1+\left(f / f_{\mathrm{c}}\right)^{2}}
$$

where $f, f_{\mathrm{c}}$, and $M_{\mathrm{o}}$ are the frequency, corner frequency, and seismic moment, respectively. A self-similar scaling law indicates that $f_{\mathrm{c}} \propto M_{\mathrm{o}}^{-1 / 3}$; thus, for $f \gg f_{\mathrm{c}^{\prime}}$, $\widetilde{M}_{\mathrm{o}}(f) \approx M_{\mathrm{o}} /\left(f / f_{\mathrm{c}}\right)^{2} \propto M_{\mathrm{o}}^{1 / 3} / f^{2}$. This relation suggests that the amplitude ratio corresponds to the cube root of the moment ratio. In other words, the moment ratio is estimated by the cube of the amplitude ratio. This relationship was also used in the definition of the magnitude by Atkinson and Hanks (1995) based on high-frequency level of acceleration amplitude spectrum. Atkinson and Hanks (1995) constructed a formula of the magnitude, whereas we measure the magnitude difference of two events.

The amplitude ratios of the accelerograms high-passfiltered at $16 \mathrm{~Hz}$ range from 3 to 13 with a median of 5 (Fig. 5). This inter-station variation in the amplitude ratios is due to many factors including the differences in source locations and focal mechanisms. Therefore, we choose the median value as the high-frequency amplitude ratio of these two events. The moment ratio of the triggered event to the $M_{\mathrm{w}} 5.1$ event is then estimated to be 125 , implying that the $M_{\mathrm{w}}$ of the triggered event was 6.5. It should be noted that this estimation is very rough because it strongly relies on the validity of the assumption of the $\omega^{2}$ model and the self-similar scaling law. Therefore, we conservatively conclude that the triggered event was a mid- $M_{\mathrm{w}} 6$ event.

\section{Discussion and conclusions}

First, we have revealed the geometries of the faults ruptured by three distinct large earthquakes. The complex fault system may have prevented the simultaneous rupture of all these faults (Anderson et al. 2003), and instead, large earthquakes occurred successively. However, it should be noted that complexities in fault geometry do not always stop earthquake rupture. For example, in the 2012 off Sumatra earthquake, multiple strike-slip faults were ruptured by a single earthquake (Meng et al. 2012; Satriano et al. 2012; Wang et al. 2012; Yue et al. 2012). In the Nankai and Tonankai megathrust earthquakes, some M8-class events ruptured one of these regions, and some events ruptured both regions simultaneously (Ando 1975). Further investigations are needed to confirm how the irregularities of fault geometries contributed the earthquake generation.

Next, we have shown that the Aso gap corresponds to the large slip area by the largest event (event $\gamma$ ). Owing to the small amount of stress remaining for aftershock production, it is often observed that fewer aftershocks occur in the fault segments with a large slip area (Mendoza and Hartzell 1988). However, it is quite unusual that fewer aftershocks in the Aso gap are observed even below the large slip area. While a rigorous discussion on the origins of the Aso gap requires further investigation of the volcanic structure and resultant fault behaviors, a high temperature due to the geotherm of Mt. Aso must play an important role. Three-dimensional magnetotelluric surveys (Asaue et al. 2012; Hata et al. 2016) identified low electric resistivity in this area. Although the interpretation of the low resistivity is still ambiguous, one can interpret the low resistivity as indication of high temperature area, because, relatively high geothermal gradient (40-90 K/ km around $1 \mathrm{~km}$ of depth) was observed in Mt. Aso (Tanaka et al. 2004a, b). Moreover, Curie-point depth (Okubo et al. 1985) in the Aso gap is shallower than that in the rupture area of the event $\gamma$. The magma chamber of Mt. Aso located west of the active crater and east of the Aso gap (Sudo and Kong 2001) will contribute the high temperature in the Aso gap. The fact that earthquakes before the Kumamoto earthquake distribute in the very shallow portion of the Aso gap (Fig. 3c) may reflect an effect of the geotherm. These observations will be a key to understand the influence of the volcanic geotherm on the formation of the Aso gap. Our fault slip model further suggests that the seismicity in the northern Aso can be interpreted as usual aftershocks of the event $\gamma$.

On the dynamic triggering event, we hypothesize that the triggered rupture reached Beppu from Yufuin, which is supported by the following empirical relation and observations: The scaling law for the fault length (Wells and Coppersmith 1994) implies a fault length of $10-20 \mathrm{~km}$ for this mid- $M_{\mathrm{w}} 6.0$ triggered earthquake; the seismicity was activated immediately after the event $\gamma$ (Fig. 1b) in the elongated zone with a length of almost $20 \mathrm{~km}$; and the In-SAR image from ALOS-2 also indicates 


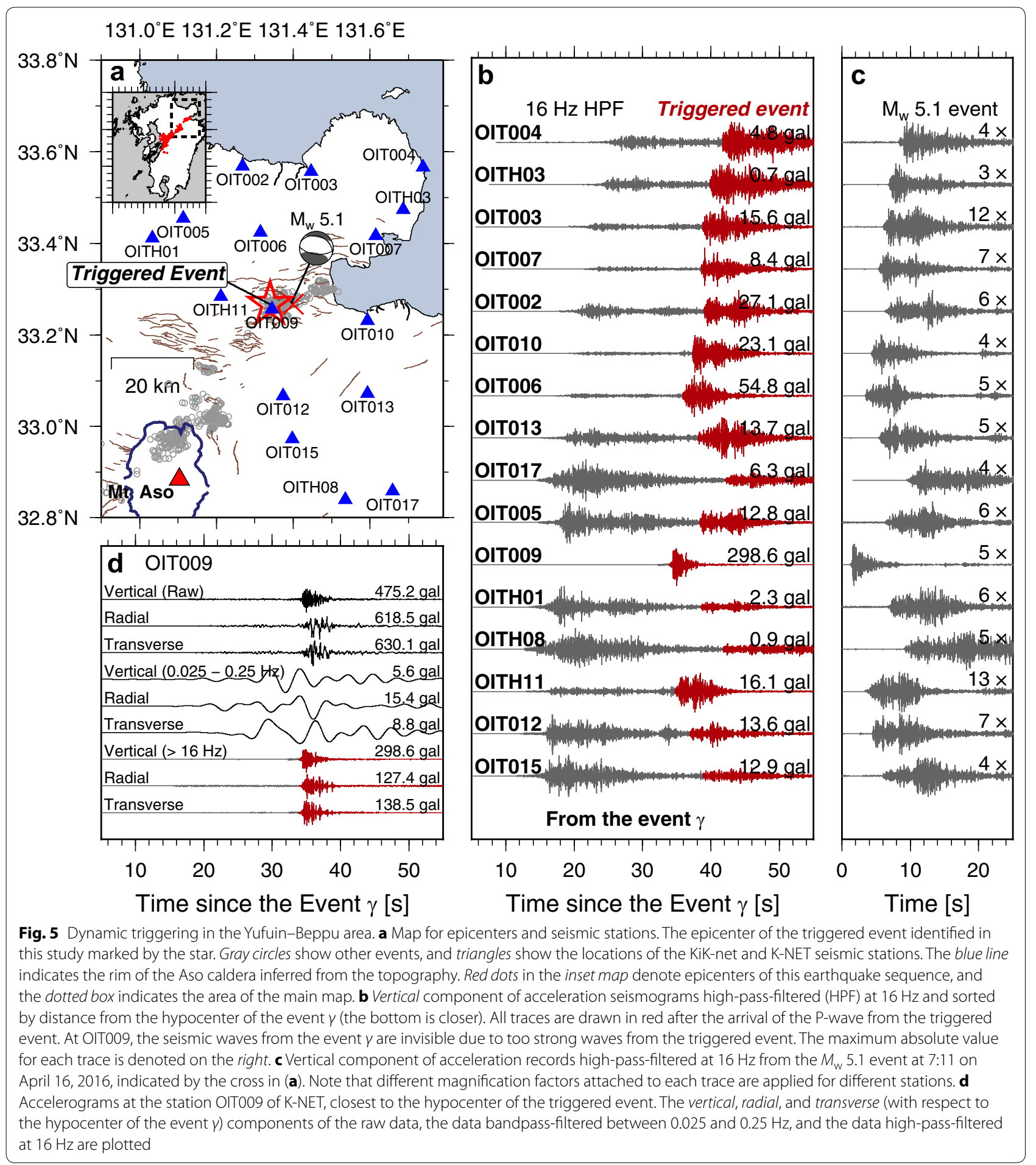

a surface offset of up to $6 \mathrm{~cm}$ for $10 \mathrm{~km}$ or longer along the surface trace of a pre-existing fault (Geospatial Information Authority of Japan 2016). This dynamic triggering mechanism produced an apparent gap in seismicity between the northern Aso and Yufuin-Beppu areas, which is different from the case in the Aso gap described above.

The features of the earthquake sequence we revealed give rise to new questions. It is important to understand the mechanism of the formation of the complex system 
of the Futagawa and Hinagu faults. The fault slip model strongly suggests that large stress accumulation is possible at shallow depths near the volcanos, where the accumulation mechanism remains an open question. Furthermore, the formation mechanism of the Aso gap is not yet fully elucidated. Here, detailed information on the structure of Mt. Aso should advance our understanding. While, in this paper, we discuss the influence of volcanic areas on earthquake generation, the effect of this earthquake sequence on the volcanic activities should also be investigated. These studies will contribute to the improvement in the accuracy of the scenarios of potential disaster in the seismo-volcano tectonics, which are used for evaluating the natural hazards posed by these events.

\section{Additional files}

\begin{abstract}
Additional file 1: Figure S1. Comparison between hypocenter locations from the JMA catalog and the relocated catalog of this study. (a) Map view in Kumamoto and Aso area. Red and gray symbols indicate epicenter locations from the JMA catalog and the relocated catalog, respectively. (b) Cross sections of the relocated earthquakes at locations $\left(A-A^{\prime}\right.$ to $\left.I-I^{\prime}\right)$ indicated in (a). The brown line on the top of each panel corresponds to the surface trace of active faults (Nakata and Imaizumi 2002). (c), (d), and (e) Change in latitude, longitude, and depth, respectively, by the relocation process. Vertical axes denote differences of the parameters of relocated catalog from those of the JMA catalog.
\end{abstract}

Additional file 2: Movie S1. Three-dimensional distribution of hypocenters in the Futagawa and Hinagu fault systems. Orange, pink, and red balls denote hypocenters of the events $\alpha, \beta$, and $\gamma$, respectively. Other balls show hypocenters of other small events classified by geometries of the distribution as indicated by color. Light blue ones are the nearly vertical fault on which the hypocenter of the event $a$ is located, whereas the vertical fault for the event $\gamma$ is not identified in this video.

\section{Authors' contributions}

TU performed all data analyses with help from $\mathrm{HH}, \mathrm{RM}$ and $\mathrm{Kl}$, and drafted the manuscript. MN produced the movie to display the hypocentre distribution in three-dimensional space. NS provided geological interpretation. RA provided comments from the viewpoint of earthquake source dynamics. All authors read and approved the final manuscript.

\section{Author details \\ ${ }^{1}$ Geological Survey of Japan, National Institute of Advanced Industrial Sci- ence and Technology (AIST), 1-1-1 Higashi, AIST Central 7, Tsukuba, Ibaraki 305-8567, Japan. ${ }^{2}$ Department of Earth and Planetary Science, Graduate School of Science, The University of Tokyo, 7-3-1 Hongo, Bunkyo, Tokyo 113-0033, Japan.}

\section{Acknowledgements}

We thank Nobuo Matsushima for providing his trace data of the caldera rim of Mt. Aso. We also thank Maki Hata, Yoshiki Shirahama, Chen Ji, one anonymous reviewer, and the Editor for their constructive comments. We used the phase data from the JMA Unified Earthquake Catalog (based on seismic data from JMA, NIED, and Kyushu University) and seismograms from Hi-net, KiK-net, and K-NET of NIED (Okada et al. 2004).

\section{Competing interests}

The authors declare that they have no competing interests.

\section{Availability of data and materials}

The datasets supporting the conclusions of this article are available in the Hi-net (http://www.hinet.bosai.go.jp/?LANG=en) and Strong-motion
Seismograph Networks (KiK-net and K-NET; http://www.kyoshin.bosai.go.jp/) of NIED.

Received: 22 July 2016 Accepted: 29 October 2016

Published online: 15 November 2016

\section{References}

Aki K (1967) Scaling law of seismic spectrum. J Geophys Res 72:1217-1231. doi:10.1029/JZ072i004p01217

Anderson JG, Brune JN, Louie JN, Zeng Y, Savage M, Yu G, Chen Q, dePolo D (1994) Seismicity in the western Great Basin apparently triggered by the Landers, California, earthquake, 28 June 1992. Bull Seismol Soc Am 84:863-891

Anderson G, Aagaard B, Hudnut K (2003) Fault interactions and large complex earthquakes in the Los Angeles area. Science 302:1946-1949. doi:10.1126/science.1090747

Ando M (1975) Source mechanisms and tectonic significance of historical earthquakes along the Nankai Trough, Japan. Tectonophysics 27:119-140. doi:10.1016/0040-1951(75)90102-X

Ando R, Okuyama S (2010) Deep roots of upper plate faults and earthquake generation illuminated by volcanism. Geophys Res Lett 37:L10308. doi:10.1029/2010GL042956

Asaue H, Kubo T, Yoshinaga T, Koike K (2012) Application of magnetotelluric (MT) resistivity to imaging of regional three-dimensional geologic structures and groundwater systems. Nat Resour Res 21:383-393. doi:10.1007/ s11053-012-9184-2

Atkinson GM, Hanks TC (1995) A high-frequency magnitude scale. Bull Seismol Soc Am 85:825-833

Azzaro R (1999) Earthquake surface faulting at Mount Etna volcano (Sicily) and implications for active tectonics. J Geodyn 28:193-213. doi:10.1016/ S0264-3707(98)00037-4

Bouchon M (1981) A simple method to calculate Green's functions for elastic layered media. Bull Seismol Soc Am 71:959-971

Brodsky EE, Karakostas V, Kanamori H (2000) A new observation of dynamically triggered regional seismicity: earthquakes in Greece following the August, 1999 Izmit, Turkey earthquake. Geophys Res Lett 27:2741-2744

Dziewonski AM, Chou TA, Woodhouse JH (1981) Determination of earthquake source parameters from waveform data for studies of global and regional seismicity. J Geophys Res 86:2825-2852. doi:10.1029/JB086iB04p02825

Ekström G, Nettles M, Dziewoński AM (2012) The global CMT project 2004-2010: centroid-moment tensors for 13,017 earthquakes. Phys Earth Planet Inter 200-201:1-9. doi:10.1016/j.pepi.2012.04.002

Fujiwara H et al (2009) A study on 'national seismic hazard map for Japan'. Technical note of the National Research Institute for Earth Science and Disaster Prevention, no 336. National Research Institute for Earth Science and Disaster Prevention, Tsukuba, Japan (in Japanese)

Fujiwara H et al (2012) Some improvements of seismic hazard assessment based on the 2011 Tohoku earthquake. Technical note of the National Research Institute for Earth Science and Disaster Prevention, no 379. National Research Institute for Earth Science and Disaster Prevention, Tsukuba, Japan, pp 1-349 (in Japanese)

Geospatial Information Authority of Japan (2016) Information on the 2016 Kumamoto earthquake. http://www.gsi.go.jp/BOUSAl/H27-kumamotoearthquake-index.html\#3. Accessed 27 Sept 2016 (in Japanese)

Gomberg J, Reasenberg PA, Bodin P, Harris RA (2001) Earthquake triggering by seismic waves following the Landers and Hector Mine earthquakes. Nature 411:462-466. doi:10.1038/35078053

Hardebeck JL, Shearer PM (2002) A new method for determining first-motion focal mechanisms. Bull Seismol Soc Am 92:2264-2276

Hartzell SH, Heaton TH (1983) Inversion of strong ground motion and teleseismic waveform data for the fault rupture history of the 1979 Imperial Valley, California, earthquake. Bull Seismol Soc Am 73:1553-1583

Hata M, Takakura S, Matsushima N, Hashimoto T, Utsugi M (2016) Crustal magma pathway beneath Aso caldera inferred from three-dimensional electrical resistivity structure. Geophys Res Lett. doi:10.1002/201 6GL070315

Hill DP, Prejean SG (2007) Dynamic triggering. Treatise Geophys. doi:10.1016/ B978-044452748-6.00070-5 
Hirata N, Matsu'ura M (1987) Maximum-likelihood estimation of hypocenter with origin time eliminated using nonlinear inversion technique. Phys Earth Planet Inter 47:50-61. doi:10.1016/0031-9201(87)90066-5

Kato A, Ji Fukuda, Nakagawa S, Obara K (2016) Foreshock migration preceding the 2016 M $_{w} 7.0$ Kumamoto earthquake, Japan. Geophys Res Lett. doi:10. 1002/2016GL070079

Kennett BLN, Kerry NJ (1979) Seismic waves in a stratified half space. Geophys J R Astron Soc 57:557-583

Kilb D, Gomberg J, Bodin P (2000) Triggering of earthquake aftershocks by dynamic stresses. Nature 408:570-574

Lawson CL, Hanson RJ (1995) Solving least squares problems, Classics in Applied Mathematics. SIAM, Philadelphia

Matsubara M, Obara K, Kasahara K (2008) Three-dimensional P- and S-wave velocity structures beneath the Japan Islands obtained by high-density seismic stations by seismic tomography. Tectonophysics 454:86-103. doi:10.1016/j.tecto.2008.04.016

Matsumoto Y (1979) Some problems on volcanic activities and depression structures in Kyushu, Japan. Mem Geol Soc Jpn 16:127-139 (in Japanese)

Matsumoto S et al (2015) Spatial heterogeneities in tectonic stress in Kyushu, Japan and their relation to a major shear zone. Earth Planets Space 67:172. doi:10.1186/s40623-015-0342-8

Mendoza C, Hartzell SH (1988) Aftershock patterns and main shock faulting. Bull Seismol Soc Am 78:1438-1449

Meng L, Ampuero J-P, Stock J, Duputel Z, Luo Y, Tsai VC (2012) Earthquake in a maze: compressional rupture branching during the $2012 M_{w} 8.6$ Sumatra earthquake. Science 337:724-726. doi:10.1126/science.1224030

Moran S, Stihler S, Power J (2002) A tectonic earthquake sequence preceding the April-May 1999 eruption of Shishaldin Volcano, Alaska. Bull Volcanol 64:520-524. doi:10.1007/s00445-002-0226-1

Nakata T, Imaizumi T (2002) Digital active fault map of Japan. University of Tokyo Press, Tokyo (in Japanese)

Nishigami K (1997) Spatial distribution of coda scatterers in the crust around two active volcanoes and one active fault system in central Japan: inversion analysis of coda envelope. Phys Earth Planet Inter 104:75-89. doi:10.1016/S0031-9201(97)00058-7

Okada Y, Kasahara K, Hori S, Obara K, Sekiguchi S, Fujiwara H, Yamamoto A (2004) Recent progress of seismic observation networks in Japan-Hinet, F-net, K-NET and KiK-net. Earth Planets Space 56:xv-xxviii

Okubo Y, Graf RJ, Hansen RO, Ogawa K, Tsu H (1985) Curie point depths of the Island of Kyushu and surrounding areas, Japan. Geophysics 50:481-494. doi:10.1190/1.1441926

Satriano C, Kiraly E, Bernard P, Vilotte J-P (2012) The $2012 M_{w} 8.6$ Sumatra earthquake: evidence of westward sequential seismic ruptures associated to the reactivation of a N-S ocean fabric. Geophys Res Lett 39:L15302. doi :10.1029/2012GL052387

Shirahama Y, Yoshimi M, Awata Y, Maruyama T, Azuma T, Miyashita Y, Mori H, Imanishi K, Takeda N, Ochi T, Otsubo M, Asahina D, Miyakawa A (2016) Characteristics of the surface ruptures associated with the 2016 Kumamoto earthquake sequence, central Kyushu, Japan. Earth Planets Space. doi:10.1186/s40623-016-0559-1 [ePub ahead of print]

Sudo Y, Kong $L$ (2001) Three-dimensional seismic velocity structure beneath Aso Volcano, Kyushu, Japan. Bull Volcanol 63:326-344. doi:10.1007/ s004450100145
Takeo M (1985) Near-field synthetic seismograms taking into account the effects of anelasticity - the effects of anelastic attenuation on seismograms caused by a sedimentary layer. Pap Meteorol Geophys 36:245-257 (in Japanese)

Tanaka A, Yamano M, Yano Y, Sasada M (2004a) Geothermal gradient and heat flow data in and around Japan (I): appraisal of heat flow from geothermal gradient data. Earth Planets Space 56:1191-1194. doi:10.1186/ bf03353339

Tanaka A, Yano Y, Sasada M (2004b) Geothermal gradient data in and around Japan. Digital Geoscience Map, vol. DGM P-5, Geological Survey of Japan, Tsukuba

The Headquarters for Earthquake Research Promotion (2002) Long-term evaluation of the Futagawa-Hinagu fault zone, 1st edn. The Headquarters for Earthquake Research Promotion. http://www.jishin.go.jp/main/ chousa/katsudansou_pdf/93_futagawa_hinagu.pdf. Accessed 28 Sept 2016 (in Japanese)

The Headquarters for Earthquake Research Promotion (2013) Long-term evaluation of the Futagawa and Hinagu fault zones (2013 rev). The Headquarters for Earthquake Research Promotion. http://www.jishin.go.jp/ main/chousa/katsudansou_pdf/93_futagawa_hinagu_2.pdf. Accessed 28 Sept 2016 (in Japanese)

Uchide T, Ide S (2007) Development of multiscale slip inversion method and its application to the 2004 mid-Niigata Prefecture earthquake. J Geophys Res 112:B06313. doi:10.1029/2006JB004528

Waldhauser F, Ellsworth WL (2000) A double-difference earthquake location algorithm: method and application to the northern Hayward fault, California. Bull Seismol Soc Am 90:1353-1368

Wang D, Mori J, Uchide T (2012) Supershear rupture on multiple faults for the $M_{w}$ 8.6 Off Northern Sumatra, Indonesia earthquake of April 11, 2012. Geophys Res Lett 39:L21307. doi:10.1029/2012GL053622

Wells DL, Coppersmith KJ (1994) New empirical relationships among magnitude, rupture length, rupture width, rupture area, and surface displacement. Bull Seismol Soc Am 84:974-1002

Yabuki T, Matsu'ura M (1992) Geodetic data inversion using a Bayesian information criterion for spatial distribution of fault slip. Geophys J Int 109:363-375

Yagi Y, Okuwaki R, Enescu B, Kasahara A, Miyakawa A, Otsubo M (2016) Rupture process of the 2016 Kumamoto earthquake in relation to the thermal structure around Aso volcano. Earth Planets Space 68:118. doi:10.1186/ s40623-016-0492-3

Yue H, Lay T, Koper KD (2012) En echelon and orthogonal fault ruptures of the 11 April 2012 great intraplate earthquakes. Nature 490:245-249. doi:10.1038/nature11492

Yukutake Y, Honda R, Harada M, Aketagawa T, Ito H, Yoshida A (2012) Remotely triggered seismicity in Hakone volcano following the 2011 Off the Pacific Coast of Tohoku Earthquake. Earth Planets Space 64:269-277. doi:10.5047/eps.2011.09.002

\section{Submit your manuscript to a SpringerOpen ${ }^{\circ}$ journal and benefit from:}

- Convenient online submission

- Rigorous peer review

- Immediate publication on acceptance

- Open access: articles freely available online

- High visibility within the field

- Retaining the copyright to your article

Submit your next manuscript at springeropen.com 